\title{
Reaching the disadvantaged: ensur- ing access to quality early childhood care and education in the estate sector of Sri Lanka
}

Sri Lanka Journal of Social Sciences and Humanities Volume 2 Issue 1, February 2022: 41-53 ISSN: 2773 692X (Online), 27736911 (Print) Copyright: (C) 2021 The Author(s)

Published by Faculty of Social Sciences and Languages, Sabaragamuwa University of Sri Lanka Website: https://www.sab.ac.lk/sljssh DOI: http://doi.org/10.4038/sljssh.v2i1.55

\author{
Samitha Udayanga ${ }^{1, *}$ \\ ${ }^{1}$ Department of Sociology, University of Ruhuna, Matara, 81000, Sri Lanka.
}

Received: 15 May, 2021, Revised: 06 October, 2021, Accepted: 20 November, 2021.

How to Cite this Article: Samitha Udayanga. (2022). Reaching the disadvantaged: ensuring access to quality early childhood care and education in the estate sector of Sri Lanka. Sri Lanka Journal of Social Sciences and Humanities, 2(1), 41-53.

\begin{abstract}
Children's health and learning during early childhood are the basis for their full participation in a society that produces favourable outcomes. But not all children grow up the same to benefit equally from regulated early childhood care and education (ECCE) policies. Therefore, this study explored context-specific barriers which disrupt the implementation of ECCE policies in selected estate communities of Sri Lanka. It also provided a possible framework of solutions to facilitate the ECCE implementation in most impoverished communities. Drawing on a case study design integrated into grounded theory, this study indicates that the ECCE is not well implemented in some estate communities due to unfavourable socio-cultural determinants. The absence of an enabling environment prevents children from access to ECCE services. Access to ECCE services can be ensured only when a localized and cultureresponsive mechanism is adopted at community levels. Adopting the globally recognized ECCE policies at local levels should be facilitated by incorporating some social engineering principles such as advocacy, enabling, and reflecting to ensure that all children have access to ECCE services without interruption and discrimination.
\end{abstract}

Keywords: Culture-responsive, Early Childhood Care and Education (ECCE), Estate sector, Localization, Socio-cultural determinants

\section{INTRODUCTION}

The present study explored certain context-specific barriers which impair the implementation of Early Childhood Care and Education (ECCE) policies at the studied estate communities of Sri Lanka. While understanding those context-specific barriers, possible solutions were also found to facilitate the effective implementation of ECCE policies at local levels. Not all young children grow up the same as the socio-cultural environment where they grow up influences their development differently. Therefore, child development can be mainstreamed in one culture, while in another culture, children can be ignored even from child development research (McLoyd et al., 2006). McLoyd et al. (2006) highlight that some young children are likely to be ignored by early childhood care and education programs. Sometimes, because of their place of origin and social identity, many young children are neglected and systematically controlled out of child care and education programs (Darling-Hammond et al., 2020). Facilitating children and their parents to access quality ECCE services would produce favourable results, yet the implementation process of those policies is highly selective and discriminatory (Baldock, 1999). Since implementing policies follows a social gradient, the existing differences and inequalities affect how local communities are approached through social policies. However, facilitating children and their parents to access quality ECCE services without discrimination is taken for granted as a prerequisite for sustainable development.
While recognizing the importance of ECCE provisions that have the potential to impact favourably on human development, Sri Lanka has adopted ECD (Early Childhood Development) policies and widened the provision of services, particularly to the most impoverished communities, including the estate sector (Children's Secretariat, 2014). ECCE provisions were first established through its public healthcare system, and in 1997, a holistic approach for ECCE was adopted following the general educational reforms (World Bank, 2014). Subsequently, several other policy frameworks have been adopted. The National Plan of Action for Children in Sri Lanka in 2016 has been the recent policy intervention (Ministry of Women and Child Affairs, 2016).

Sri Lanka has progressed toward providing good and quality ECCE programs in line with the recommendations for sustainable development goal (SDG) 4 on education (Warnasuriya et al., 2020; World Bank, 2014). But several challenges were encountered, particularly in the estate sector. Ensuring access to quality health care and education, particularly for the most disadvantaged, is the target of the sustainable development agenda, but endeavours to provide ECCE services encounter several challenges in the developing world (Davis, 2010). Therefore, intending to ensure that all children have equal access to quality care and education services, Sri Lanka has systematically identified some issues and challenges (Pathirana, 2017). However, how socio-cultural determinants shape the implementation of ECCE

\footnotetext{
* Corresponding author: Tel.: +94716376070; Email: kasamitha@soci.ruh.ac.lk (iD) https://orcid.org/0000-0002-9826-691X
} 
policies was not studied adequately. In particular, the National Child Policy of the country contends that there is a lack of research on the cultural dimension of ECCE policy implementation. Therefore, this study has explored how certain socio-cultural determinants affect the implementation of ECCE policies in selected estate communities of Sri Lanka and proposed a locally relevant policy approach to facilitate the policy implementation process.

\section{LITERATURE REVIEW}

Ensuring access to quality health care and education, particularly for the most disadvantaged, is one of the promising targets of the sustainable development agenda, but endeavours to provide ECCE services encounter several challenges. This study has thus explored how socio-cultural determinants affect ECCE policies in the estate sector of Sri Lanka and proposes a locally relevant policy approach to facilitate implementing such policies. Agenda 2030 for sustainable development is the monumental policy document, which redirects humanity toward a sustainable future (UN, 2017). For a sustainable world, the agenda posits that individuals are required to become sustainability change-makers (catalyst agents) (UNESCO, 2017). This is where lifelong learning begins at birth and carries through all stages of life comes forth (UNESCO, 2016). Life-long learning is strengthened in early childhood so that systematic interventions are required to ensure access to ECCE services for children without discrimination.

Quality education that produces change-makers is one of the key areas of human wellbeing captured by SDGs' fourth goal. Change-makers of the sustainable development process (agents of sustainable development) must have the necessary knowledge, skills, values, and attitudes that empower them to contribute to the sustainable development process (UNESCO, 2016). However, a handful of studies indicate that many children in disadvantaged communities in South Asia are not developmentally on track in health, learning, and psychosocial wellbeing. As a result, they are not ready for formal primary education (Brainerd \& Menon, 2015). In the meantime, some international-level policies are planned to ensure access to quality education, even though it requires local level specifications as the problems grounded in specific socio-cultural contexts are difficult to be addressed through globally accepted yet locally unspecified policies (Belda-Miquel et al., 2019; Escobar, 2011; Tayler, 2011). Thus, this research also explored how local knowledge supports achieving access to quality ECCE in the estate sector of Sri Lanka.

Every stage of life of a person can be enlightened by education, especially for the poor, marginalized, and the most vulnerable (Engle et al., 2011). Education is the key that will allow the other sustainable development goals to be achieved. When children can get a quality education, they can break the cycle of poverty (Engle et al., 2011; Vijayakumar \& Brezinova, 2012). Education, therefore, helps to reduce inequalities. It also empowers people to live more healthy and sustainable lives. Education's unique potential to act as a catalyst for wider development goals can only be realized if it is equitable. Therefore, making special efforts to ensure all children regardless of their family income, the place of living, gender, ethnicity benefit equally from its transformative power has been regarded as a global policy priority (UNESCO, 2016). Education empowers children, in particular, by increasing their chances of getting jobs, staying healthy, and participating fully in society. Education is a common basis for all dimensions of sustainable development, and no advances in sustainable development will occur without multiple generations contributing to social development in the coming years.

Although different cultures define early childhood education differently, it is believed that students everywhere must acquire some basic skills, such as interpreting written pages, basic calculation, understanding how numbers work, etc. (UNESCO, 2015). The World Bank specified that "people must learn how numbers work or some logical abilities so that they can buy and sell in markets, set family budgets, interpret loan agreements" (World Bank, 2017, p. 4). In addition, socio-emotional skills such as perseverance and the ability to work on teams are important to help people acquire and apply the foundational and other skills more sustainably. Quality education, therefore, should equip students with skills, knowledge, and attitudes essential for a better life.

The quality of lifelong learning and education, which is more inclusive and equitable, begins at the age of the pre-natal era in which the parent's and family members' support is required. A parent's knowledge and awareness about the future born child are important since it affects the offspring. Thus, the very beginning stage of lifelong learning can be widely influenced by the social structure, since early childhood is a stage where decision-making about themselves is not possible. Children are less likely to make grounded decisions with prudence, and hence providing parental or societal support to the offspring will produce favourable results in later stages of life (Santrock, 2011).

This research mainly focused on early childhood development (ECD), which is phenomenal in achieving a prosperous life. The 2030 Agenda signifies that ECD will be of the highest priority for the sustainable development of the twenty-first century. Target 4.2 explicitly mentions that by 2030 , all the member countries should ensure that all girls and boys have access to quality early childhood development, care, and pre-primary education to be ready for primary education (Alexander et al., 2013). Lifelong learning begins and is strengthened in early childhood, and hence investments and awareness on this stage are critical in many perspectives. A handful of studies on ECD have found that critical care and investments in early childhood lead to empowerment, better health and education outcomes, improved skills that are necessary for future education and career life (Frongillo et al., 2017; Munthali et al., 2014; UNICEF, 2015; Yoshikawa et al., 2018). Furthermore, quality early childhood care and education will narrow the income disparities, ethnic and gender gaps, and it is a cost-effective strategy for eliminating discrimination and social inequality (Woodhead, 2016).

Scholars have emphasized the importance of good care for children in their earliest years; this belief itself is embedded in many cultural traditions (Udayanga, 2021; UNICEF, 2017). "Belief in the need for proper care is also grounded in the recognition that children are the next generation; they represent the continuity of tradition as well as the hope for, and fear of, change" (Mayers, 1992, p. 3). Therefore, early childhood care concerns nutrition, psychosocial wellbeing, a safe environment, and stimulating children. Furthermore, it is argued that there is a positive relationship between sustainable early childhood and upcoming stages of life (Young, 2000). Although early childhood begins at birth and continues toward the age of eight, the first five years are more important in strengthening the child's wellbeing. Quality of 
early childhood care and education thus ensures that children are ready for primary education and their future educational prospects.

Although early childhood development, care, and education policies were properly planned and initiated in specific cultural settings, some unexpected obstacles might deflate its progress (Udayanga et al., 2021). This can be more commonly seen in excluded and disadvantaged communities in every country (Clert, 1999; Sen, 2000). Disadvantaged communities refer to the areas in a country that most suffer from a combination of economic, health, and environmental burdens. These burdens include poverty, high unemployment, and poor health conditions (Sen, 2000). The estate sector (or plantation sector) in Sri Lanka has been identified as an excluded and disadvantaged society (Gunetilleke et al., 2008). For a considerable period, the estate sector seems to have been excluded and placed in a disadvantaged position due to various reasons, particularly because of their social identity (Bass, 2012; Hollup, 1994).

The total population in Sri Lanka is a little over twenty million as of 2012, of which 4.4 percent of the population $(901,647)$ inhabit the estate sector (Department of Census and Statistics, 2017). Many plantation sector people were recorded in Nuwaraeliya district (53.5\%), following Badulla district $(18.9 \%)$. The country's child population under the age of five is $8.6 \%$, and it was reported to be a slight decline compared to previous years, and a considerable number of children come from the estate sector. As far as multidimensional poverty is concerned, the estate sector shows a significantly high rate at 0.1134 than urban and rural sectors. In that, 11.3 percent of the estate population is multidimensionally poor (Department of Census and Statistics, 2020). Vulnerable to the multidimensional poor index is 0.2242 among the estate population. The highest number of multidimensional households $(12.4 \%)$ is in the estate sector. Therefore, the progress of ECCE programs is highly likely to be downgraded in that estate sector, compared to the other sectors of the country.

The estate sector (commonly known as the plantation sector) in Sri Lanka can be distinguished from other social sectors (urban and rural), owing to its unique subculture and social organization. The estate sector consists of tea and rubber plantations managed by the state, plantation companies, or individual families. The estate sector refers to land over twenty acres with ten or more indentured resident workers (Bandarage, 1982; Wesumperuma, 1986). The majority of upcountry (Indian origin) Tamils reside in the estate sector where tea plantations are established. The plantation population consists of about 902,000 persons, of which $72 \%$ live in Nuwaraeliya and Badulla districts. Furthermore, due to several reasons, the estate sector remains one of the most disadvantaged and marginalized communities (Ananda, 2018; Dawood, 1980; Gunetilleke et al., 2008; Ranathunga \& Gibson, 2015).

The estate sector exclusion and marginalization were considered a result of systematic discrimination by the state, even though some argue that discrimination against the estate sector has resulted from cultural identity contestations (Hollup, 1994; Wesumperuma, 1986). These communities often depend on plantation companies because their very presence is attributed to indentured or bonded labour in plantations. For example, to obtain a house or a living place, plantation labourers must provide their service to the plantation company unless they cannot claim a place of living (Wesumperuma, 1986). Thus, even though the estate sector has been considered an integral part of the political landscape in the country, it reflects distinguishingly important structural characteristics from that of urban and rural societies in Sri Lanka. These structural determinants affect development interventions in the estate sector.

Although the welfare of plantation migrant labourers was out of concern during the mid-nineteenth century, the British colonial government introduced several legislations related to the welfare of plantation labourers. Under the state-driven laws and regulations, private plantation companies were advised to provide transportation, shelter, and basic healthcare facilities besides food and temporary lodging (Bandarage, 1982). Thus, South Indian Tamil immigrant labourers were rarely claimed for their rights, which compelled them to create a unique identity contesting with mainstream social norms and values (Piyarathne, 2008; Wesumperuma, 1986). During the 1880s, the British government established medical care facilities to reduce death rates among immigrant Tamil labourers and elevate their health to contribute to the plantation labour force. For several decades, the government and private plantation companies contested welfare service provision and policies in the estate sector (Arunatilake, 2000).

The plantation sector was introduced to some basic education facilities under the purview of the government, even though implementing this policy was recognized as a responsibility of plantation companies (Mohammed et al., 2019). Thence, a few hill country schools were established, but early childhood education and care were neglected (Senavirathna \& Senavirathna, 2019).

After 1911, upcountry Tamils were officially classified as "Indian Tamils". Following British constitutional reforms, they have introduced some regulations regarding human rights, universal suffrage, etc. Still, due to a less recognition and narrow definition, 'Indian Tamils' have subsequently been excluded from the mainstream. It was only in 1984, Indian Tamils were granted citizenship. However, Indian Tamils in the plantation sector continue to develop a unique identity without thinking about assimilation. The state thus identified the estate communities as a separate social sphere characterized by a unique subculture. Therefore, when social policies are implemented in the estate sector, how estate communities respond to them can differ from responses received from urban or rural sectors.

Despite some socio-economic improvements, the estate sector in Sri Lanka still suffers from severe societal problems, including issues around early childhood development, care, and education. Moreover, the importance of early childhood care and education is considered a prerequisite for national development, contributing to the global expectation of educating all. Therefore, this study focused on understanding the obstacles that severely affect early childhood education, particularly in most disadvantaged communities.

\section{METHODOLOGY}

Informed by constructivist and interpretivist epistemological positions, this study has employed a qualitative research strategy. Framework for data collection and analysis was based on explorative-case study design. The constructivist grounded theory with an embedded single-case design was employed (Bryant \& Charmaz, 2019; Yin, 2003). Although using a research design has been an inevitable part of the positivist research tradition, it is not mandatory to employ a design in grounded theory research (Bryant \& Charmaz, 2019). However, this research has been informed by a case study 
design for the purposive selection of study fields. A case study for constructivists is "an empirical inquiry that investigates a contemporary phenomenon in context; when the boundaries between the phenomenon and the context are not evident, multiple sources of evidence are used" (Yin, 2003, p. 13).

Among several case study designs, an embedded single-case design was employed in this research. The primary focus of the study was on the estate sector in Sri Lanka as a marginalized and most vulnerable community. Studies show that estates are extremely vulnerable to poverty and health hazards and are characterized by a unique culture (Gunatilaka et al., 2009; Piyarathne, 2008; Udayanga, 2018). Because this study intends to identify socio-cultural determinants affecting ECCE policy implementation in the estate sector of Sri Lanka, the estate sector was considered the principal context being studied.

Since the primary focus of this study is on ECCE provisions for most disadvantaged communities, the estate sector in Sri Lanka has been selected as the study context. Plantation communities in the country show some distinguishing characteristics that of other sectors of Sri Lanka. Furthermore, tea plantation communities differ from rubber plantation communities; in that upcountry, Tamils largely inhabit upcountry tea plantations. Overall, $4.4 \%$ of the estate population was reported, and Nuwaraeliya, Badulla, and Kandy districts are occupied a larger proportion of the overall estate population (Department of Census and Statistics, 2012). Therefore, five estates from those three districts were purposively selected as embedded units of this single-context case study.

1. Glassaugh estate, Nanuoya, Nuwaraeliya,

2. Labookele estate (Upper-division and Lower division), Nuwaraeliya

3. Frotoft estate, Nuwaraeliya

4. Ury Estate, Passara, Badulla

5. Perawatta estate, Galaha, Kandy

Tea plantations were widely in the hill country during the British colonial period (Bandarage, 1982). After 1984, upcountry Tamils were granted citizenship as a political strategy, even though it was not an attempt to ensure their wellbeing. Still, after several positive law reforms concerning upcountry Tamils, they remain one of the most discriminated and marginalized communities in Sri Lanka (Mohammed et al., 2019). The poverty headcount ratio of the hill country Tamils decreases, even though their multidimensional poverty is on the gradual rise. Besides, several developmental indicators are the furthest behind among the estate population (Ministry of Hill Country New Villages Infrastructure and Community Development, 2019; Mohammed et al., 2019). Some recognize the reason for this as the long-standing structural discrimination against them (Piyarathne, 2008).

For the worthiness and authenticity of data, triangulation of methods, such as in-depth interviews, empirical observations, and focus group discussions, were employed. Participants in the sample were recruited through the purposive sampling method. Five focus group discussions were conducted, and forty in-depth interviews were carried out. Data collection was carried out in line with the principle of 'data category saturation' (Saunders et al., 2018). The paper presents the analysis thematically (Lorelli S. Nowell, Jill M. Norris, Deborah E. White, 2017).

\section{OBJECTIVES OF THE STUDY}

The overall objective of this study is to explore context-specific barriers affecting the implementation of ECCE policies in the estate sector of Sri Lanka. Even though some have identified implementation issues of early childhood education and care and policy in disadvantaged communities, how dispositional characteristics informed by distinctive sociocultural determinants affect implementing policies of ECCE have not been recognized. This study has thus focused on the following objectives:

a) To understand the current state of early childhood care and education provisions in the estate sector.

b) To explore localized policy approaches to facilitate ECCE policies in the estate sector of Sri Lanka.

\section{FINDINGS}

The present study has found that quality early childhood care and education is less likely to happen in the estate sector, as learners are unprepared due to some unsupportive socio-cultural and environmental determinants. In collaboration with non-government organizations, the government has established early childhood development centres in estate communities, even though their contribution to providing a good and quality education for children is considerably low due to different reasons of which structural determinants are detrimental. Although some developments regarding early childhood care and education have been observed, the existing policy model is less likely to be associated with the estate community environment. Universal health coverage in the country is specifically attentive to health care in estate communities. Midwifery service in estate communities is thus properly organized so that appointed midwives advocate community members about health as well as early childhood education.

Early childhood care and education have been recognized as a mainstream policy arena for the most disadvantaged communities, and some policies have been implemented despite some contextual issues encountered. Therefore, this study shows how the social structure affects ECCE in the estate sector and possible grounded approaches to facilitate existing policy models for ECCE service provisions in the estate sector.

\section{Early childhood education and unprepared learners}

Early childhood education in estate communities is now gaining significant concern as estate dwellers are conscientious about the importance of education and its impact on their future life, even though adults are lethargic about facilitating the education of their toddlers. As people strive to live with daily needs and instant satisfaction, no culture has been developed that values education investment. Investments in education have not been considered as investments for their future prosperity. Hence, a large portion of income is spent on immediate needs instead of early childhood care and education. Although some parents and community members value the importance of ECCE, they are likely to be drifted from this concern because of the uncooperative subculture characteristics of the estate community. Thus, facilitating students with a conducive environment for quality education has been difficult, as estate community structure hinders it while creating a culture that does not support progressive endeavours.

Bonded or indentured labour is one of the causes that drifts parents from their concerns toward education, as parents have to work on estates consuming a considerable amount 
of time, even though amended laws have reduced their burden to some extent.

"My husband went to Colombo for a contract job, and I am working here as a labourer of the estate so that my first child looks after her four siblings. She has already dropped out of school, and my youngest boy could not constantly go to the ECD centre, as there is no responsible person to look after him". (Woman, 30year-old)

Moreover, during the past few years, no robust community role model has been developed who achieved a better social state through education in the community. This is another cause that prevents children from their education. Except for a very few cases, no person has achieved a better state in the society through education, but some have been mobilized due to non-formal economic activities such as selling vegetables on the road, contract works so that parents also try to follow those examples while separating their children from education. Thus, it was found that providing experiences about role models to estate children can make their plans successful. A 4-year-old child describes:

"One day, I want to become a police officer because police officer can solve every problem."

Children set their goals in line with everyday experiences so that when no productive experiences are encountered, children cannot set their purpose of life appropriately. For example, it was observed that when adults sell flowers to visitors and travellers on the roadsides, some small children are accompanied. They are highly likely to deviate from education, as adults' experiences compel them to engage in income generation actively. This further reduces students' enthusiasm for education. Lifting enthusiasm for education further damages the cognitive capacities to learn.

The existing curriculum in ECD centres (Early Childhood Development Institutions) in estate communities has not been well-adjusted to the community specifications so that students are less likely to absorb the content relevant knowledge; this reduces enthusiasm. For example, playing with building blocks is one thing that children should learn. Psychologist believes that playing with building blocks enhances the cognitive and executive skills of students (Schroeder \& Kelley, 2010), even though it was understood that playing with building blocks improves frustration among students because that is limited only to ECD centres, and they do not have playing materials in their houses as such.

Furthermore, the estate sector differs from the mainstream community of Sri Lanka. Therefore, centre-based child care is more critical than family-based child care. Generally, the family in the estate sector cannot provide necessary care for children, so properly planned centre-based child care and education are essential. Some important practices a child should learn from the family might not be possible in the estate sector so that when the curriculum is planned, activities that nurture students to learn good practices must be incorporated (such as brushing teeth, washing hands before a meal, everyday cleanliness).

Less resilient-age-appropriate social relationships are another determinant that deviates children from their childhood. This is a significant determinant as children feel a severe lack of age-appropriate and resilient social relationships; they might strive to imitate non-relevant and age-inappropriate behaviors. Early age marriage is one of the consequences of this, and that in turn causes several other problems related to early childhood education. Some children cannot have age-appropriate social relationships so that children do not develop their cognitive, executive, and socioemotional skills. For example, when they could not have a resilient parent-child relationship, they could not develop cognitive, executive, and socioemotional skills properly. Although midwives advocate for community members about establishing resilient and age-appropriate social relationships are crucial, it is a challenging task for them.

"I experienced over the past two decades that the age of eighteen is not an appropriate age for women to get married because they are not mentally mature to face some family issues and to bear a child. They are just like children. How can a child bear a child? How can a child take care of children?. Even young men are not mentally mature to build a stable family life. That is why many are having extramarital relationships." (Woman, 29-year-old)

Exposure to violence and neglect during early childhood is another determinant that has devastating effects. Violence among intimate partners in a family is highly likely to make a non-suitable environment for children. In this research, any violent incident against early childhood was not reported, even though violence against women is common in many cases. This might impact on cognitive development of children severely. Because parents could not make children's immediate environment a friendly place, children are unable to be developmentally on track in psychological wellbeing; consequently, education in early childhood can be endangered. In addition, child neglect is another reason for the less and inactive participation in early childhood education.

"In the daytime, I play with my sister, but she does not have much time as she has to do several things like collecting firewood, cooking. Grandma is always not responding to me as I expect. Mother comes in the evening, though she does not have much time to stay with me as she has to prepare dinner for the family" (a 5year-old-child).

Children are neglected unconsciously, and it affects children severely, as nursery teachers noted. During pre-primary school times, children reflect on their internalities among peers so that teachers can identify any abnormal behaviours of children. Teachers' role in such cases is vital, even though they were not well-trained for that. Early childhood education in estate communities in Sri Lanka has been predominantly considered in the welfare policy of the country, but some obstacles were met, as noted above.

\section{Disposition and decision making on ECCE}

In addition to the unpreparedness of children as described in the above theme, dispositional impact on decision-making can have critical implications for ECCE. The awareness of ECCE among estate dwellers can be ensured while encouraging them to work toward it only when they are motivated to make informed decisions while considering the importance of ECCE. However, this process might be failed if estate dwellers refuse to consider the ECCE as a matter of concern in their lives. It would not be easy to implement successfully some ECCE programs in the estate community because community members are not ready to involve in such programs and encapsulate practices leading to ECCE into their existing lifestyle. Besides, general support for ECCE in the estate families is lacking. This is because of their realization that ECCE is to be a secondary concern that can only be attended only when primary concerns are fulfilled. 
"We always struggle for daily survival. Especially in off seasons, we do not have enough money to buy food. What we need is to secure our lives. Before we do anything, we should first be survived. How can we send our children to CDCs (Child Development Centers) when at least they are not adequately fed with nutritious food? Somehow, we try our level best to feed our children, and in that, we think little about nutrition, but just giving something to reduce hunger." (Man, 30year-old)

The ECCE is considered being a secondary concern and is likely to be less attended to as the primary concerns (such as securing everyday life) are prioritized. This decision is aligned with the unique disposition of the estate community members.

The cultural organization of economic activities within the estate sector allows estate dwellers to understand primary Figure 1: Influence of Socio-cultural Factors on the disposition and secondary needs separately and prioritize following lifeworld reflections. Conceptualizing and recognizing the needs of community life follow a social gradient, and thus what matters to everyday life is recognized by estate dwellers while reflecting their disposition in society. Disposition or habitus refers to an individual's societal place in complex socio-cultural and economic arrangements. It is how individuals of a particular community make sense of the social world surrounding them. Unique characteristics of the estate community influence how this generic disposition of an individual is created. For example, deep-rooted marginalization and social exclusion, chronic and multidimensional poverty, ethnic origin of the community, capabilities of community members shape the disposition. This initial recognition of personhood determines how life-world desires and needs are perceived and prioritized

\begin{tabular}{|c|}
\hline Health Care Deficiency \\
\hline Excluded Mentality \\
\hline Ethnic Origin \\
\hline Fewer facilities \\
\hline Fewer Capabilities
\end{tabular}
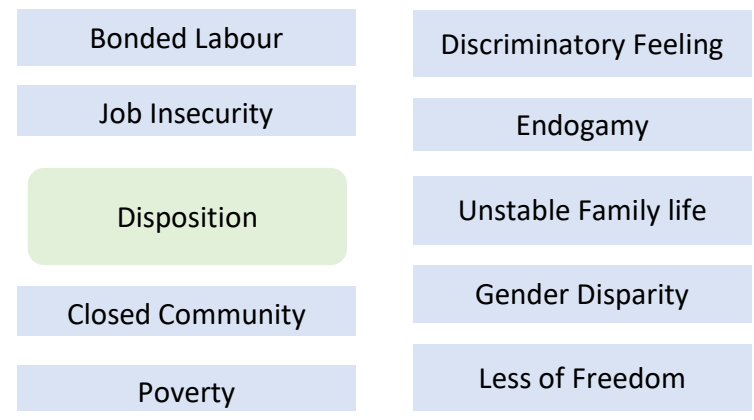

Note: This figure illustrates factors influencing the disposition of community members.

The disposition determines and affects how desires and needs of community life are fulfilled through culturally accepted means. Because disposition consists of the overall personality qualities of a person (as indicated in Figure 1), the decisions taken by that person can be influenced by such dispositional attributes. The needs of the life-world are distinguished and hierarchically arranged, responding to the nexus between the need for survival and maximum support that people can obtain. Initially, basic needs and secondary needs are recognized and prioritized, reflecting their societal situation. Primary needs are concerned based on the uncompromising/hard-line principle. The hard-line principle refers to the inability to compromise or neglect the needs and the maximum support of the person because neglecting to fulfill primary needs is life-threatening. On the other hand, secondary needs (including the ECCE) can be compromised and are satisfied only when primary needs are fulfilled. Estate dwellers are often constricted into primary needs due to several socio-cultural and economic reasons, and they are deprived of thinking about secondary needs. This negatively influences ECCE at the estates and by implementing ECCE policies.

\section{Figure 2: Influence of the disposition on decision making}

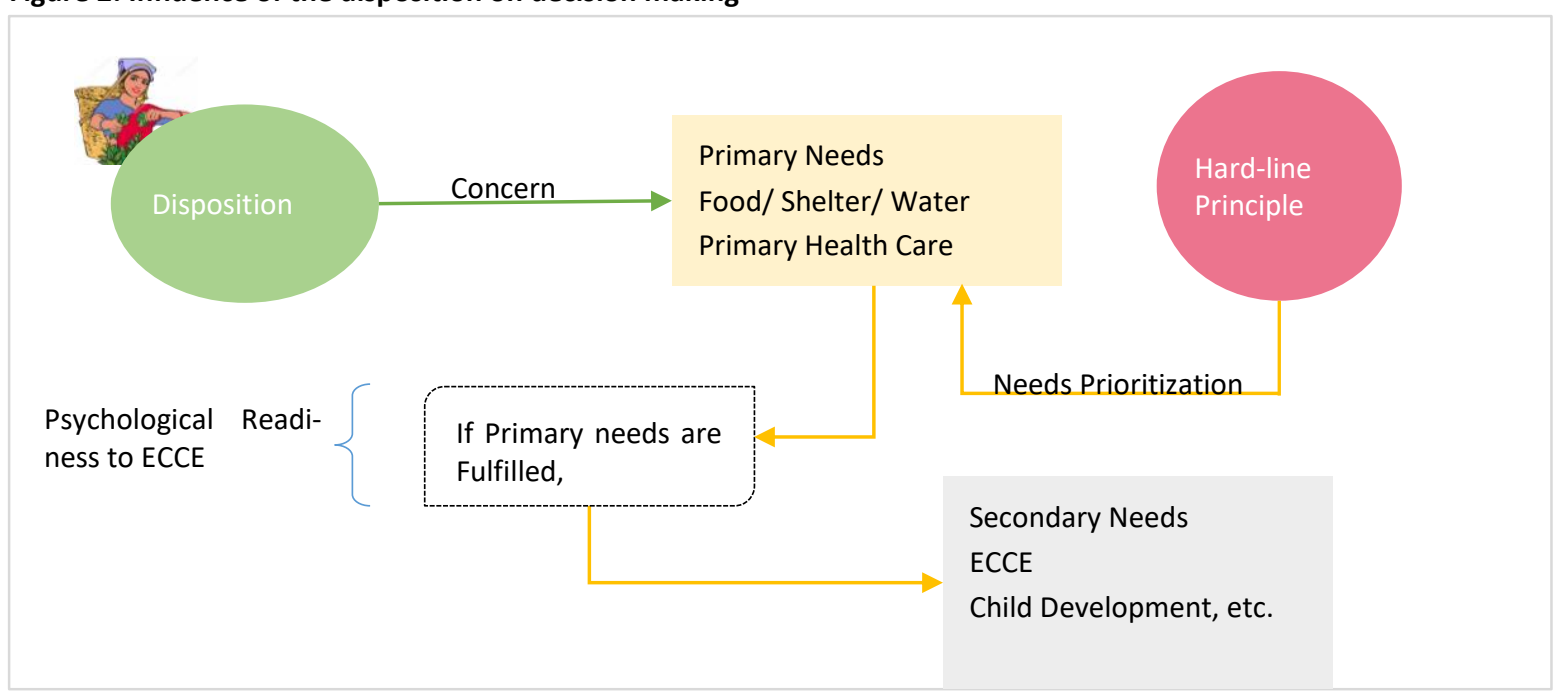

Note: The figure illustrates how the disposition of a person influences decision-making and shows how primary and secondary concerns in family life are formulated and conceived. 
As shown in Figure 2, the ECCE is considered a secondary need as it does not relate to the hard-line principle, which means that ECCE is not a requirement for everyday living as estate dwellers understand. "Concertation" among parents on secondary needs will then be attended only when primary needs are satisfactorily attended. When it fails, they will be trapped in a cycle of primary need concentration. As community members understand, the ECCE comes after primary needs. Therefore, psychological readiness to ECCE is difficult to develop as parents and community members are trapped in a cycle of concern only in primary needs due to the instability of income and family instability. As estate dwellers do everything to attend to primary needs; paradoxically, the concern on ECCE is likely to be neglected.

Implications of capabilities deprivation on ECCE in the estate sector

The early childhood care and education services are likely to be considered less critical, and ECCE is not given adequate attention because of the deprivation of capabilities of both parents and children. Sen (1999) describes "capabilities" as freedom and various opportunities that one has, even if one does not exercise all those opportunities. Opportunities are functioning; that is what a person can be or do. Capabilities deprivation of both parents and children produces an unfavourable environment for ECCE in estate communities. Following Sen's (1999) explanation, this study explored how parents and children are devoid of essential capabilities so that ECCE is left aside in the estate sector. For ECCE to become well realized at local levels, the capabilities of community members should be developed. Still, their essential capabilities are disrupted in the estates due to several sociocultural and economic constraints, which prevent them from focusing on ECCE.

This study found that the capability deprivation among parents results from a set of socio-cultural and economic causes such as multidimensional poverty, less concentration on secondary needs, the difficulty of fulfilling primary needs, patriarchal values, monogamous occupation dimension, and job insecurity. Some essential capabilities are the physical quality of healthcare, love, and care, mental wellbeing, bodily integrity and safety, participation, freedom from economic and non-economic exploitation, and time autonomy. These essential capabilities are absent among estate parents. What happens in childhood is intrinsically related to the capabilities with which an adult ends up. Therefore, when capabilities are deprived, estate dwellers are unable to capacitate their children to become familiar with ECCE.

The ability to be physically healthy and enjoy a life of normal length has been considered a prioritized capability that estate dwellers are often devoid of. Societal exclusion, geographical marginalization, lack of access to healthcare facilities, and traditional cultural norms prevent them from being physically healthy and enjoying a life of normal length. Parents often show some milder symptoms of general physical ailments, and parents seem to neglect such symptoms to worsen further due to the high cost of consulting a doctor. As explained above, mental wellbeing is deprived among parents to a considerable extent due to the stress conditions caused by extreme poverty and insecurity of occupation.

"Traveling to Balangoda town is very rare in Nagrak. There are about fifteen kilometres from Nonperail to Nagrak, and Nagrak can only be reached by foot. No public transportation is available. Therefore, inter-city travel is limited. They have to spend about six thousand rupees if they hire a trishaw, which is somehow not bearable. People thus inherently refuse to travel". (Man, 32-year-old)

In addition to the capabilities deprivation of parents, children are deprived of some capabilities which fail ECCE in the estate sector. Children's access to household income and some essential resources provide them with an encouraging and favourable opportunity to participate in ECCE programs and be ready for early stimulation. Their capabilities support children's readiness to ECCE, and therefore awareness of the ECCE can be declined when capabilities are deprived. The access to household income and some essential resources does not solely guarantee the children's readiness for ECCE, but for that, adequate access to household income is required as that would translate into favourable outcomes.

"Now we focus on our second child; he is schooling. Because we should spend money on his requirements, the amount allocated for the other two children (under five years) is minimum. There are situations where our second child cannot be given appropriate school materials when we try to help other children." (Woman, 38-year-old)

The capability of accessing household income and resources is an essential requirement of ECCE. However, inadequate access to resources at the household due to a large number of family members and needs prioritization issues, some estate children under the age of five are deprived of the ability to access household income and resources to enable them for early stimulation. The lack of income, basic needs prioritization, unbearable number of members in the household can marginalize estate children from adequate and satisfactory access to household income. This has negative implications for early childhood care and education.

Love and intimate relationships are two other vital capabilities (Nussbaum, 2011), which generally strengthen within the household through effective and proper parental support. Intimate and caring relationships between children and parents and family members provide a feeling of security and stability, which are essential requirements of child care and education. Child protection from abuse and rights violation has been one of the inevitable capabilities of children, which helps prepare a child with overall wellbeing. The bodily integrity or freedom regarding physical wellbeing depends on the love and intimate relationships among family members. However, except for a few incidents, much of the children in the estate lack love and intimate relationships, partly because of the carelessness of parents. When parents undergo a complex cycle of poverty and excessive work lord, love and intimacy can be neglected. Therefore, children are getting used to living independently, which can often be affected by the neighbourhood. Children under the age of five are thus not well prepared for pre-primary education and have not cared appropriately.

For example, a parent (29-year-old) in Glassaugh said to me that her four-year-old child is behaving arrogantly because he refuses to interact with her intimately, believing that she was responsible for his father's suicide (as she believes). The father of this child was committed suicide and was seen by the child. While listening to the malicious rumours in the neighbourhood regarding this suicide, this child now refuses to have intimate relationships with his mother. Because the family's breadwinner had died, the mother now has to feed the family with five members. She currently works as a tea plucker and as a housemaid in the evening times. This prevents her from intimate relationships with her children. The neighbourhood too aggravates how the four-year-old child 
behaves. Therefore, this child refuses to attend CDC and acts as though he is not a family member. A fourteen-year-old daughter has to take care of the other two children when the mother works outside. This case demonstrates how some capabilities have been deprived of both parents and children.

Love and affectionate relationships have been neglected while deviating children from their ability to have solid and deep relationships with parents and family members. This has been aggravated due to the neighbourhood's influence. Because the breadwinner has died, the mother receives no adequate support, and consequently, the fourteen-year-old daughter has to take care of other children. This might impair her emotional development as she does not receive age-appropriate experiences. Besides, two children under the age of five are not receiving parental care, which can damage their emotional development while weakening the required stimulation.

Overall, capabilities deprivation due to socio-cultural reasons described above can negatively affect early childhood care and education in the estate sector. Children are mainly unprepared, and parents are less concerned about early care and education because their essential capacities are severely damaged.

\section{Deprivation of primary health care and ECCE}

Early childhood care is closely related to primary health care. Early childhood care includes actions that ensure child health, nutrition, protection, and psychosocial improvement. Primary health care thus has implications for early childhood care and education. Early childhood education is possible only when children are healthy to involve in core education activities. Recently, it has been understood that inculcating twenty-first-century skills among children should begin during early childhood (Sylva et al., 2020). However, early care is a prerequisite for early education to be obtained successfully. Often in the estate communities, primary health care conditions are very low, so that children are not healthy to take part in CDC activities.

"Often estate children are vulnerable to malnutrition and other biological and psychological diseases as they are not properly socialized for primary health care practices. Children's brain development follows a social gradient and parental support, and child development outcomes might be jeopardized when parental support is not received appropriately." (Woman, 31year-old)

Personal hygiene is considered a precondition of early childhood care and education. Children's hygiene is severely endangered in the estate sector because of health care neglect and non-adherence to primary health care practices. Because the line-house environment is relatively unclean, children can often expose to bacterial diseases. Both children and parents rarely wear footwear, so the bacterial disease is prevalent. As midwives and some NGO officials emphasize, people are less likely to follow certain primary health care guidelines no matter how much they are advised. This is because estate dwellers have not been properly trained to follow primary health care practices. As explained above, toilet use is relatively minimal. Washing hands using soap, maintaining bodily cleanliness are some important primary health care practices, but midwives note that estate parents are less likely to follow such practices and to train their children to follow those practices.
Furthermore, oral health is decreasing among estate children since children are not well-trained to brush their teeth and have certain informed food habits. For example, children under the age of five usually eat Murukku (a local flour mixed sweet), which has devastating consequences for oral health. Besides, children are being used to beetle chewing because their parents are heavily adapted to chew beetle. However, some child development officers (CDOs) and midwives guide children under the age of five and their parents to follow proper health care practices despite many difficulties. That has brought about favourable outcomes during the past few years.

Moreover, breastfeeding has been considered an essential element of early health care. However, breastfeeding is significantly minimum in the estate sector and can prevent children's brain development. Breastfeeding is less concerned because of parents' negligence, mainly. After the first three months of a newborn child, estate women refrain from breastfeeding as they work on estates in the daytime. Mothers believe that breastfeeding is not a good practice, believing that children have to be independent without relying on their parents. Therefore, breastfeeding is often discouraged even by older adults. Estate children often show some characteristics of stunting and wasting, mainly because of less breastfeeding, therefore.

"Children should not be trained to rely on breastfeeding, because when we are not at home, it would be really difficult to care for them. So that we often discourage breastfeeding and try to train children to milk powder or for hard-food." (Woman, 26-year-old)

Some of the existing food habits are not good enough for ECCE on the estate at all. The main purpose of food consumption among estate dwellers is to address the immediate need of hunger but not support nutritional requirements. This has dangerous implications, particularly for children's brain development during early childhood. (Some parents were married at a very early age, and thus, they cannot fathom some primary health care practices good for children.) Therefore, malnutrition is prevalent, and that can have a negative impact on early education.

Existing beliefs about nutrition and food consumption might prevent parents from focusing on healthy food habits. For example, preparing a balanced diet is considered difficult in the estates simultaneously working on estates. Estate workers thus tend to cook roti as the main staple food and are consumed with tea. This is not a good food habit and for nutrition, even though it has been prevalent. Cooking is a part of the culture and the life-world, but it has been considered a burden. Cooking has not been given a cultural value so that it is restricted just to preparing food for mere consumption. The selection of food, concerning on nutritional requirements are not concerned much, therefore. Food selection often depends on the immediate fulfilment of hunger. The focus of parents in the estate is concerned only with food for mere survival. Accordingly, sufficient time is not allocated for food preparation, as parents are busy with many other important tasks. This compels people to fulfill their hunger needs by mere means, which impairs child care and education.

Primary health care for children is weakened, on the other hand, because of alcohol addiction by parents. Alcohol addiction is generally a distinguishing subculture feature of the estate sector, and this can negatively affect early childhood care and education. Not just men, but women are, in some 
cases, addicted to alcohol. Even though some are not addicted, but many tend to drink beverages including arrack, beer, and local toddy. Alcohol consumption is generally justified by community members saying that "it soothes the stress conditions, and helps warm up within a cooler climate". Alcohol consumption is harmful to children in different dimensions. For example, unnecessarily, a large amount of daily wage is allocated for beverages while not giving adequate attention to care and development needs. Often domestic violence can be instigated because fathers are addicted to alcohol, which ultimately prevents providing an enabling environment for children to obtain good and quality ECCE services.

Grounded model for early childhood education
Some studies have introduced models to ensure an enabling environment for early childhood development and education (Pearson, 2015; Vargas-Barón, 2013, 2016; World Bank, 2014), but this study proposes a model that can support policy advocates and policymakers in integrating grounded knowledge into their globally recognized policies. In order to ensure that all children under the age of five in estate communities have access to quality early childhood care and education, three principles of action must be taken into consideration by both policymakers and community members. When globally accepted policies are implemented at local levels, local knowledge shall be integrated to reflect local realities effectively. Undoubtedly, globally accepted policies should be implemented at local levels, which can be further enhanced by incorporating local knowledge and culture-specific approaches. Figure 3 demonstrates how a grounded model can integrate into global policy initiatives.

Figure 3. Three principles of action and integrating it with global policies
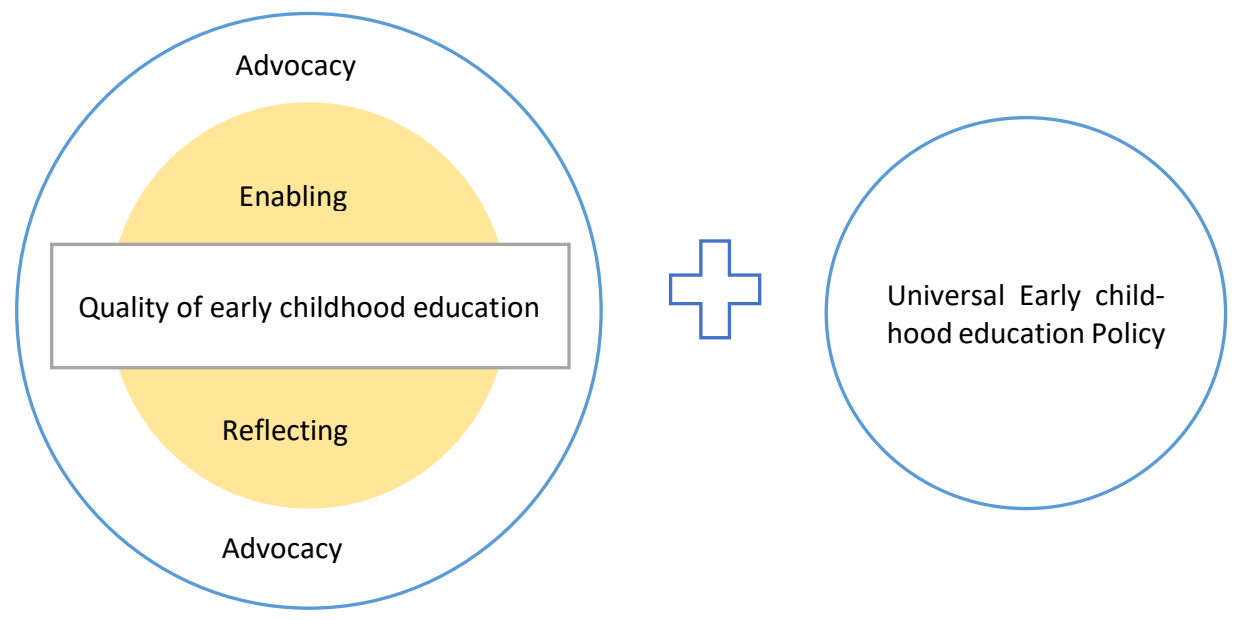

Note: Advocacy, Enabling, and Reflections are those principles of action, all of which facilitate children to acquire quality early childhood care and education; in fact, those principles of action help construct an enabling environment that enables children to engage in productive education.

\section{Advocacy}

Community advocacy refers to engaging in purposeful actions that will help people advance their rights, opportunities, and human dignity (Miyahara \& Meyers, 2008; Pawar, 2014). In order to make an enabling environment for early childhood education, the first principle is to advocate for parents and community members appropriately. State-community and private sector partnerships are crucial in this regard, as different personnel can advocate helping people realize their strengths. Case advocacy would be more effective in this process, as advocates can identify community needs and unique qualities that affect the policy implementation process. Causes advocacy is ineffective here, as each case (children) should be understood and advocated carefully. Case advocacy is based on a detailed understanding of each case, which is complex and time-consuming. Therefore, public-private and community partnership is an integral part of this process.

Community advocacy services can be implemented in local communities by refining existing midwifery services. Midwives' role in specific communities can be refined to advocate for community members about early childhood care and education. Midwives are responsible for mothers' and children's health in communities; furthermore, this responsibility consists of assisting in reproductive health. Since midwives are already engaged in community health, they are ideal for the community advocacy process. This research found that providing training about the importance of ECE (Early Childhood Education) for midwives can help community members ensure a conducive environment for children to learn effectively.

Social workers' role is important in this regard; therefore, social workers must be trained to work with these communities. First, they must be given training on culture and the way of life in the estate sector of Sri Lanka. Since culture influences the life-world (Ryan \& Graue, 2009), social workers must learn their culture first. Then they should find possible paths to advocate community members, including parents, children, and significant others. In addition, religious leaders in the estate sector in Sri Lanka can inspire community members by engaging community advocacy process. Their ideologies, however, can differ from that of globally accepted policies. Therefore, midwives, social workers, and other advocates should work together with community leaders to construct a proper model suitable to their community.

Providing dedicated resources for community-based learning is one of the policy recommendations of this research, but that can only be realized if advocates can cooperate with communities and government institutions cooperatively. The cooperative role of advocates determines the community readiness for early childhood education. In addition, 
government and NGO help can be obtained through cooperation through which community needs can be properly identified and addressed.

The community advocate's role is depicted in Figure 4. External advocates should learn the culture of the community before they engage in advocacy, and internal advocates in the community should particularly understand how culture influences people's life-world. Once they understand the community's culture, they can cooperate with people to understand individual cases where learned theories and skills can be employed. After that, advocates should reflect on Figure 4. Case- advocacy process their experiences with community members about the extent to which the learned theories and skills are relevant in the community they work on. In addition, advocates should learn about individual cases, which is the core of case advocacy that helps them advocate appropriately. Once advocates can understand individual cases where assistance is needed, they can assist them regarding ECD. Family counselling is important for this activity. In the end, advocates should reflect their engagement in the community through which new skills and experiences can bring about future progress.

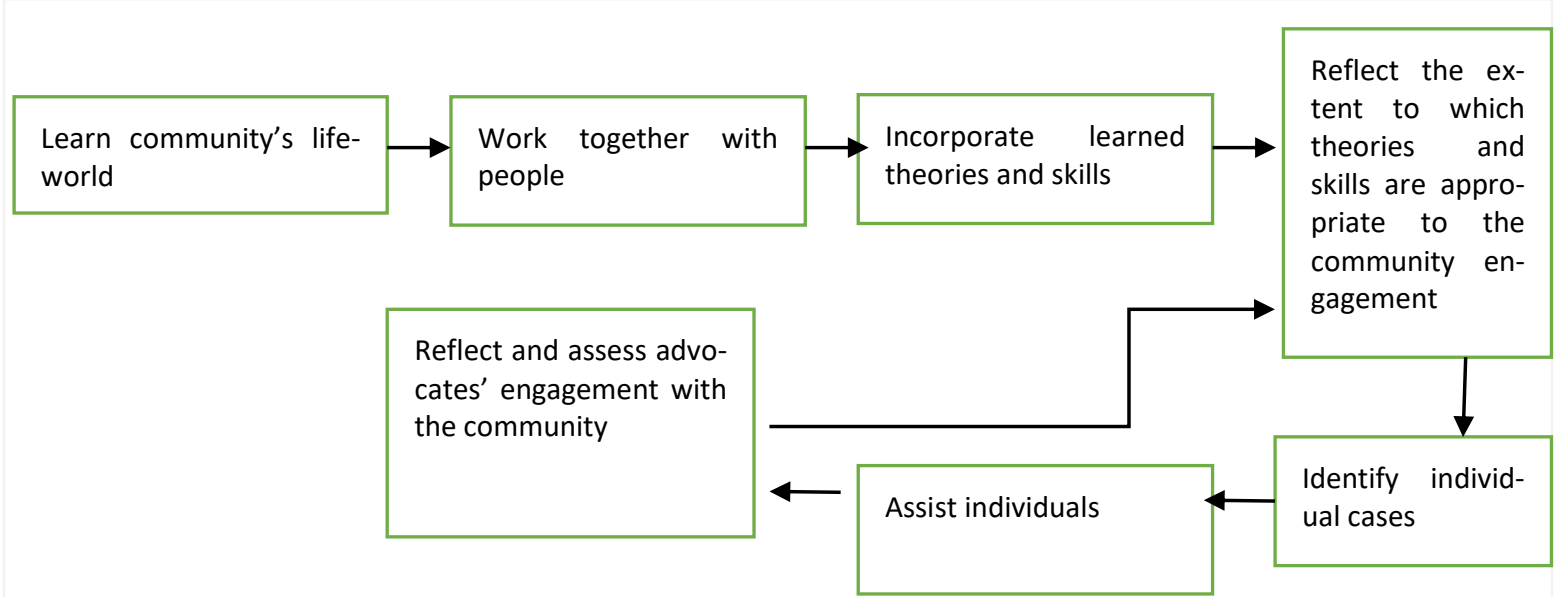

Note: This figure depicts the flow of case advocacy that can be adopted in estate communities.

\section{Enabling}

Enabling is a process through which community members are given essential capabilities to change their lives better. Enabling empowers people to reflect on their lives. Capacity building is one activity that can be performed to enable people to make informed and responsible decisions. Giving capacity to members would empower them to change their existing lifestyle to better fit with the changing society. In order to enable people economically, proper carrier guidance can be provided. In addition, enabling them with financial literacy would help them manage their family budget effectively and properly. Advocates must involve community members in participatory workshops in order to provide knowledge about financial literacy. Small-scale entrepreneurial activities can be implemented in communities; this is particularly important for women. Nonetheless, women's role in early childhood development and education is crucial, so that midwives must advocate for women regarding early childhood development, care, health, and education.

Furthermore, the health and nutrition of parents and children is a significant determinant that influences early childhood care and education. For a healthy life, thus members of a community should be equipped with reproductive literacy. Children can be provided nutritional food with the help of government authorities and private sector contributions. Experience-oriented workshops and programs can be organized, and community members' participation should be obtained. People shall be given a platform to acquire new knowledge and share their existing experiences with other community members with the same interest.

Enabling community members includes uplifting enthusiasm of children to learn, participatory curriculum revision, providing biographical examples of those who acquired greater success in their lives. In addition, making self-help groups, arranging social networks, organizing cultural programs to promote early childhood education would be worthwhile. While reading, writing, and mathematical skills will continue to be essential, new knowledge and skills such as using computer applications would further enhance the capabilities of children.

This model emphasizes the child-centred approach in which children are given considerable consideration, and the surrounding environment is adjusted accordingly. Organizing cultural programs and involving children is thus vital to promote early childhood care and education among children to gain the community's attention. Introducing information and communication technology is another policy recommendation that enhances children's soft skills in early childhood.

\section{Reflecting}

Reflecting is an evaluative process that enables us to look back and evaluate the experiences of people. Reflecting principle is vital for both community members and advocates. As noted above, advocates must reflect on their experiences about cooperation with community members, whereas community members shall be guided to reflect on their recent experiences about life. Thus, reflecting acts as a feedback mechanism. Children can also be trained to reflect on their recent past, which would facilitate them in identifying their weaknesses and elevate strengths.

Reflection is an integral part of the community advocacy process, in that advocates should compare their previous experiences with new experiences while integrating them with learned theories and skills. Advocates should help local authorities and non-governmental organizations organize community workshops to share experiences of people who reflect their lives. Carefully planned periodical workshops can be organized for children, for which nursery teachers, advocates, and midwives' guidance and assistance are recommended. An exemplary session plan for students is portrayed in case 1. 


\section{Case 1: Primary Health Care Activity}

Phase 1: The teacher brought toothpaste, toothbrush, soap to the class. In addition, she taught children about primary health care in simple words that provided answers for basic questions such as,

- Why should we brush our teeth?

- Advantages of brushing teeth?

- How to brush teeth properly?

- How to wash our faces?

- Why should we use a separate towel?

Phase 2: After a week, the teacher asked students to draw a picture of their experience regarding brushing their teeth. Then she asked children to demonstrate it in the class while explaining the advantages of it.
Case 1 presents a basic plan for reflecting sessions for children. This enables children to rethink their experiences with primary health care.

The happiness index is another tool that can be used to reflect children's emotional state in their immediate environment. This is a graphical representation of children's previous emotional states (moods). The happiness index provides nursery teachers, midwives, and other social workers to understand psychological wellbeing among students. This is a simple reflective activity students can involve in that students are asked to indicate their emotional state using an emotion emoji. There are four emotion-emoji, such as happy, sad, neutral, and delighted. The happiness index facilitates students to reflect on how they felt over some time. Teachers and other social workers can also understand the state of psychological wellbeing among students. An example of a happiness index is demonstrated in figure 5 .

Figure 5. A model of a Happiness Index

\begin{tabular}{|l|l|l|l|l|l|l|l|l|}
\hline $\begin{array}{l}\text { Name of } \\
\text { the child }\end{array}$ & $\begin{array}{l}\text { Day } \\
\text { Sam }\end{array}$ & $\begin{array}{l}\text { Day } \\
\mathbf{2}\end{array}$ & $\begin{array}{l}\text { Day } \\
\mathbf{3}\end{array}$ & $\begin{array}{l}\text { Day } \\
\mathbf{4}\end{array}$ & $\begin{array}{l}\text { Day } \\
\mathbf{5}\end{array}$ & $\begin{array}{l}\text { Day } \\
\mathbf{6}\end{array}$ & $\begin{array}{l}\text { Day } \\
\mathbf{7}\end{array}$ & $\begin{array}{l}\text { Day } \\
\mathbf{8}\end{array}$ \\
\hline David & $\ddots$ & $\ddots \bullet$ & $\ddots$ & $\ddots$ & $\ddots$ & $\ddots$ & $\ddots$ \\
\hline Samantha & $\ddots$ & $\ddots$ & $\ddots$ & $\ddots$ & $\ddots$ & $\ddots$ & $\ddots$ & $\ddots$ \\
\hline
\end{tabular}

Note: A happiness index is used to demonstrate the emotional states of children graphically. Source: Above model is carved out using the happiness index displayed at the CDC in Frotoft estate.

The happiness index is a simple but effective tool to identify children's emotional attachments to society. Moreover, this facilitates students to reflect on how they lived with their families. Social workers and those who engage in early childhood development and education policy activities would be able to identify psychological wellbeing among children by analyzing the happiness index and can intervene where necessary. This index further supports identifying individual cases where assistance is required.

Reflection is thus an integral component of the model proposed for quality early childhood education and development. Reflection facilitates community members and advocates to reflect on their experiences regarding the progress of activities about early childhood education and development. Action plans for early childhood education of a particular community can be assessed in line with reflections of different stakeholders, whereby adjustments that bring further progress in communities can be made.

\section{CONCLUSIONS}

Early childhood care and education are integral parts of lifelong learning that enhance children's capacities to face different issues in their lives. The sustainable development agenda has captured this requirement carefully and articulated in the fourth goal. The goal aims to achieve equitable, good, and quality education for all with no discrimination by 2030, which early childhood education has captured as an indispensable target. Many international institutes work toward achieving this goal, but developing countries face unexpected difficulties. Reaching the disadvantaged communities has been one of the policy issues that policy advocates and social workers face when they engage with people. This is true for Sri Lanka; in a sense, estate communities where tea plantations were located face difficulties, particularly regarding early childhood development and education.

Early childhood development and education in the Sri Lankan estate sector have been improving during the past few years due to government and non-governmental organizations' interventions. However, some structural barriers hinder the progress to a greater extent. This study has found that learners in early childhood are less likely to be prepared for education as their attention is diverted elsewhere due to the community's unpreparedness toward providing good and quality early childhood education for their children. In addition, bonded labour, less appreciation of education, social drift, lack of experiences among parents and significant others, less resilient-age appropriate social relationships, exposure to violence and neglect would cause a lack of participation and inactive participation in early childhood care and education. Thus, this research proposed a more culture-specific method to make the environment conducive so that students are prepared for early childhood care and education.

When globally accepted policies are implemented at local levels, it has been assumed that localization is essential, and 
hence, this proposed model can be incorporated with globally accepted policies. The model consists of three components: advocacy, enabling, and reflection. Advocacy is an overarching component in that community members, advocates, and available social workers should be trained to identify individual cases and facilitate them to encourage children toward early childhood education. Furthermore, different activities are included in the enabling process through which people are enabled to perform some selected activities to concern early childhood care and education. In addition, reflection is another component that provides feedback about the overall progress. These three components are essential to localize globally accepted policies to achieve the stipulated target in the goal.

Therefore, the research concludes specifying that proper placement of sustainability supportive qualities and characteristics in programs implemented at local levels, particularly in disadvantaged communities, is of critical importance to child's self-actualization so that they are prepared for early learning, which in turn makes "change makers" for sustainable development.

\section{REFERENCES}

Alexander, J., Fayyad, K., Forner, R., Greubel, L., Gustafsson-Wright, E., Matsui, E., Robinson, J. P., Gaag, J. van der, \& Fleet, J. van. (2013). Toward Universal Learning: What Every Child Should Learn (Vol. 1). The UNESCO Institute for Statistics.

Ananda, S. (2018). Up-country Tamils and Cultural Indebtedness: The Case of Chronic Poverty in the Plantation Sector in Sri Lanka. Rajarato University Journal, 3(2), 105-120.

Arunatilake, N. (2000). Effectiveness of Welfare Programmes in Improving Estate Performance in Sri Lanka. In Research Studies: Human Resources Development Series No. 4 (Vol. 53, Issue 9). Institute of Policy Studies of Sri Lanka.

Baldock, J. (1999). Culture: The Missing Variable in Understanding Socia Policy? Social Policy and Administration, 33(4), 458-473. https://doi.org/DOI: 10.1111/1467-9515.00163

Bandarage, A. (1982). The Establishment and Consolidation of the Plantation Economy in Sri Lanka. Critical Asian Studies, 14(3), 2-22. https://doi.org/10.1080/14672715.1982.10412654

Bass, D. (2012). Everyday Ethnicity in Sri Lanka. Routledge. https://doi.org/10.4324/9780203097809

Belda-Miquel, S., Boni, A., \& Calabuig, C. (2019). SDG Localisation and Decentralised Development Aid: Exploring Opposing Discourses and Practices in Valencia's Aid Sector. Journal of Human Development and Capabilities, 20(4), 386-402. https://doi.org/10.1080/19452829.2019.1624512

Brainerd, E., \& Menon, N. (2015). Religion and Health in Early Childhood: Evidence from South Asia. Population and Development Review 41(3), 439-463. https://doi.org/10.1111/j.1728-4457.2015.00067.x

Bryant, A., \& Charmaz, K. (2019). The SAGE Handbook of Current Developments in Grounded Theory. SAGE Publication Ltd.

Children's Secretariat. (2014). National Policy on Early Childhood Care and Development. The Ministry of Women and Child Affairs. http://34.196.27.239/storage/app/media/National Policy english.pdf

Clert, C. (1999). Evaluating the Concept of Social Exclusion in Development Discourse. The European Journal of Development Research, 11(2), 176-199. https://doi.org/10.1080/09578819908426743

Darling-Hammond, L., Flook, L., Cook-Harvey, C., Barron, B., \& Osher, D. (2020). Implications for the educational practice of the science of learning and development. Applied Developmental Science, 24(2), 97-140. https://doi.org/10.1080/10888691.2018.1537791

Davis, J. M. (2010). What is early childhood education for sustainability? In Young Children and the Environment: Early Education for Sustainability (pp. 21-42). Cambridge University Press. https://doi.org/10.1017/CBO9780511845390.003
Dawood, N. (1980). Tea and Poverty: Plantations and the Political Economy of Sri Lanka. Urban-Rural Mission, Christian Conference of Asia., xii, 166 p. https://catalogue.nla.gov.au/Record/1334604

Department of Census and Statistics. (2012). Census of Population and Housing

2012. http://www.statistics.gov.lk/PopHouSat/CPH2011/Pages/Activities/ Reports/CPH_2012_5Per_Rpt.pdf

Department of Census and Statistics. (2017). Demographic and Health Survey 2016. Ministry of National Policies and Economic Affairs.

Department of Census and Statistics. (2020). Global Multidimensional Poverty for Sri Lanka.

Engle, P. L., Fernald, L. C. H., Alderman, H., Behrman, J., O'Gara, C., Yousafzai, A., De Mello, M. C., Hidrobo, M., Ulkuer, N., Ertem, I., \& Iltus, S. (2011). Strategies for reducing inequalities and improving developmental outcomes for young children in low-income and middle-income countries. In The Lancet (Vol. 378, Issue 9799, pp. 1339-1353). Elsevier. https://doi.org/10.1016/S01406736(11)60889-1

Escobar, A. (2011). Sustainability: Design for the pluriverse. Development, 54(2), 137-140. https://doi.org/10.1057/dev.2011.28

Frongillo, E. A., Kulkarni, S., Basnet, S., \& de Castro, F. (2017). Family Care Behaviors and Early Childhood Development in Low- and MiddleIncome Countries. Journal of Child and Family Studies, 26(11), 30363044. https://doi.org/10.1007/s10826-017-0816-3

Gunatilaka, R., Wan, G., \& Chatterjee, S. (2009). Poverty and human development in Sri Lanka. Asian Development Bank. https://www.adb.org/sites/default/files/publication/27993/poverty -human-dev-sri-lanka.pdf

Gunetilleke, N., Kuruppu, S., \& Goonasekera, S. (2008). The Estate Workers' Dilemma: Tension and Changes in the Tea and Rubber Plantations in Sri Lanka. CEPA.

Hollup, O. (1994). Bounded Labour Cast and cultural identity among Tamil plantation workers in Sri Lanka. Sterling Publishers.

Lorelli S. Nowell, Jill M. Norris, Deborah E. White, N. J. M. (2017). Thematic Analysis: Striving to Meet the Trustworthiness Criteria. International Journal of Qualitative Methods, 16, 1-13. https://doi.org/10.1177/1609406917733847

Mayers, R. (1992). The Twelve Who Survive: Strengthening programmes of early childhood development in the third world. Routledge.

McLoyd, V. C., Aikens, N. L., \& Burton, L. M. (2006). Childhood Poverty, Policy, and Practice. In K. A. Renninger, I. E. Sigel, W. Damon, \& R. M. Lerner (Eds.), Handbook of child psychology: Child psychology in practice (pp. 700-775). John Wiley \& Sons Inc.

Ministry of Hill Country New Villages Infrastructure and Community Development. (2019). Performance Report. http://www.mceeid.gov.lk/web/wpcontent/uploads/2019/11/Performance-Report-2018-English.pdf

Ministry of Women and Child Affairs. (2016). The National Plan of Action for Children 2016-2020 (NPA). https://www.endviolence.org/sites/default/files/paragraphs/download/National plan of action for children in Sri Lanka 2016-2020.pdf

Miyahara, J., \& Meyers, C. (2008). Early learning and development standards in east Asia and the Pacific: Experiences from eight countries. International Journal of Early Childhood, 40(2), 17-31. https://doi.org/10.1007/BF03165837

Mohammed, R., Razick, S., Dias, R., de Chickera, A., \& Gunatilleke, G. (2019). Hill Country Tamils of Sri Lanka: Towards Meaningful Citizenship. Verité Research. www.veriteresearch.org

Munthali, A. C., Mvula, P. M., \& Silo, L. (2014). Early childhood development: The role of community-based childcare centres in Malawi. SpringerPlus, 3(1), 1-10. https://doi.org/10.1186/21931801-3-305

Nussbaum, M. (2011). Creating Capabilities: The Human Development Approach. Harvard University Press.

Pathirana, B. D. D. (2017). Evolution of Early Childhood Care and Development (ECCD) in Sri Lanka: Analysis of the state responsibility. International Journal of Scientific Research in Science and Technology, $3(6), 37-43$.

Pawar, M. (2014). Social Work Practice With Local Communities in Developing Countries Imperatives for Political Engagement. In SAGE Open Journal of International Social Work (pp. 1-11). https://doi.org/10.1177/2158244014538640 
Pearson, E. C. (2015). Moving forward with early childhood care and education (ECCE) post-2015 in the Asia Pacific Region: an analysis of global and national policy goals. International Journal of Child Care and Education Policy, 9(1), 1-19. https://doi.org/10.1186/s40723015-0016-9

Piyarathne, A. (2008). Longing for equal status: Impact of housing intervention on identity and status of Indian origin Tamil resettlers from two selected plantations in Sri Lanka. Sri Lanka Journal of Socia Sciences, 31-32(1-2), 47-63. https://doi.org/10.4038/sljss.v31i12.5463

Ranathunga, D. S., \& Gibson, J. (2015). The factors determine household poverty in the estate sector in Sri Lanka. Global Business and Economics Research Journal, 4, 2302-4593.

Ryan, S., \& Graue, M. E. (2009). Examining a lifeworld: Early childhood policy in practice. In Contemporary Issues in Early Childhood (Vol. 10 Issue 3, pp. 190-193). https://doi.org/10.2304/ciec.2009.10.3.190

Santrock, J. W. (2011). Child Development. McGraw-Hill Education.

Saunders, B., Sim, J., Kingstone, T., Baker, S., Waterfield, J., Bartlam, B., Burroughs, H., \& Jinks, C. (2018). Saturation in qualitative research: exploring its conceptualization and operationalization. Quality \& Quantity, 52(4), 1893-1907. https://doi.org/10.1007/s11135-0170574-8

Schroeder, V. M., \& Kelley, M. L. (2010). Family environment and parentchild relationships as related to executive functioning in children. Early Child Development and Care, 180(10), 1285-1298. https://doi.org/10.1080/03004430902981512

Sen, A. (1999). Development As Freedom. Oxford University Press.

Sen, A. (2000). Social Exclusion: Concept, Application, And Scrutiny. Asian Development Bank. https://www.thinkasia.org/bitstream/handle/11540/2339/socialexclusion.pdf?sequence $=1$

Senavirathna, R. M. N. N., \& Senavirathna, R. M. N. S. (2019). School Dropout among Young Girls in the Estate Sector in Matale District of Sri Lanka. International Journal of Governance and Public Policy Analysis, 1(1). http://dr.lib.sjp.ac.lk/handle/123456789/8891

Sylva, K., Sammons, P., Melhuish, E., Siraj, I., \& Taggart, B. (2020). Developing 21st-century skills in early childhood: the contribution of process quality to self-regulation and pro-social behaviour. Zeitschrift Fur Erziehungswissenschaft, 23(3), 465-484. https://doi.org/10.1007/s11618-020-00945-x

Tayler, C. (2011). Changing Policy, Changing Culture: Steps Toward Early Learning Quality Improvement in Australia. In International Journal of Early Childhood (Vol. 43, Issue 3, pp. 211-225). Springer. https://doi.org/10.1007/s13158-011-0043-9

Udayanga, S. (2018). Cognitive Orientation as a determinant of quality learning experiences in early childhood education. International Journal of Research and Development, 3(12), 1-10.

Udayanga, S. (2021). The Impact of Family Environment and Family Management on Early Childhood Care and Education in the Estate Sector of Sri Lanka. Journal of Social Sciences and Humanities Review, 6(1), 39-64.

Udayanga, S., Herath, D., \& Ekanayake, P. (2021). Socio-cultural determinants affecting early childhood care and education policy in the estate community of Sri Lanka. 18th Academic Sessions of University of Ruhuna, 53.

UN. (2017). The Sustainable Development Agenda. United Nations. http://www.un.org/sustainabledevelopment/developmentagenda/\#8e74e7178ec1f94c8

UNESCO. (2015). Education 2030: Incheon Declaration and Framework for Action for the implementation of Sustainable Development Goa 4. http://unesdoc.unesco.org/images/0024/002456/245656e.pdf

UNESCO. (2016). Education for people \& planet: Creating sustainable futures for all. UNESCO Institute for Lifelong Learning. http://gemreport-2016.unesco.org/en/home/

UNESCO. (2017). Education for Sustainable Development Goals. United Nations Educational, Scientific and Cultural Organization. http://unesdoc.unesco.org/images/0024/002474/247444e.pdf

UNICEF. (2015). National Integrated Early Childhood Development. In Government of South Africa. Government Printers. https://planipolis.iiep.unesco.org/sites/planipolis/files/ressources/s a_national_integrated_ecd_policy_2015.pdf

UNICEF. (2017). Early Childhood Development: The Key to a Fill and Productive Life. UNICEF. https://www.unicef.org/dprk/ecd.pdf
Vargas-Barón, E. (2013). Building and Strengthening National Systems for Early Childhood Development. In P. R. Britto, P. L. Engle, \& C. M. Super (Eds.), Handbook of Early Childhood Development Research and Its Impact on Global Policy (pp. 603-610). Oxford University Press. https://doi.org/10.1093/acprof

Vargas-Barón, E. (2016). Policy planning for early childhood care and education: 2000-2014. Prospects, 46(1), 15-38. https://doi.org/10.1007/s11125-016-9377-2

Vijayakumar, S., \& Brezinova, O. (2012). Poverty Incidence and its Determinants in the Estate Sector of Sri Lanka. Journal of Competitiveness, $4(1)$ https://doi.org/10.7441/joc.2012.01.04

Warnasuriya, R., Sosale, S., \& Dey, S. (2020). Integrating Early Childhood Care and Education in Sri Lanka : From Global Evidence to National Action. The World Bank.

Wesumperuma, D. (1986). Indian Immigrant Plantation Workers in Sri Lanka: A Historical Perspective, 1880-1910. The University of Michigan.

Woodhead, M. (2016). Early Childhood Development in the SDGs. Young Lives Oxford Department of International Development (ODID). https://www.younglives.org.uk/content/early-childhooddevelopment-sdgs

World Bank. (2014). Laying the foundation for early childhood education in Sri Lanka. https://openknowledge.worldbank.org/bitstream/handle/10986/23 362/Laying0theOFouOnd0investing0forOall.pdf?sequence $=1$

World Bank. (2017). Learning to Realize Education's Promise. The World Bank. https://doi.org/10.1596/978-1-4648-1096-1

Yin, R. K. (2003). Case Study Research: Design and Methods (Vol. 5). SAGE.

Yoshikawa, H., Wuermli, A. J., Raikes, A., Kim, S., \& Kabay, S. B. (2018). Toward High-Quality Early Childhood Development Programs and Policies at National Scale: Directions for Research in Global Contexts. Social Policy Report, 31(1), 1-36. https://doi.org/10.1002/j.23793988.2018.tb00091.x

Young, M. E. (2000). From Early Child Development to Human Development: Investing in Our Children's Future. The World Bank. 
